\title{
Referencial para design de infográficos digitais aplicáveis na educação profissional e tecnológica
}

Lélia Caetano*

Luís Otoni Meireles Ribeiro**

Resumo

O presente artigo relata estudo que propõe um referencial para design de infográficos digitais aplicáveis na educação profissional e tecnológica. A partir da análise de 423 infográficos foi sistematizado um repertório de elementos de linguagem da infografia. A estratificação dos dados chegou à identificação dos principais elementos básicos de linguagem e dos principais elementos que caracterizam a representação de cada tipo de conhecimento. A pesquisa fornece elementos para analisar as demandas de representação do conhecimento e orientar educadores e equipes de produção de material didático, quanto aos requisitos para criação e ou seleção de infográficos que venham contribuir com objetivos de ensino-aprendizagem.

Palavras-chave: infográficos, design, educação profissional e tecnológica

1 Mestre em Educação. Especialista em Educação. Designer Educacional. leliacaetano.ic@gmail.com 2 Doutor em Informática na Educação. Mestre em Tecnologia - Educação Tecnológica. Especialista em Educação Continuada e a Distância. Especialista em Controle de Processos. Professor MPET/IFSul luis.otoni@gmail.com 


\section{A guide for the design of digital infographics applied to professional and technological education}

\section{Referencia para design de infografías digitales aplicables en la educación profesional y tecnológica}

\begin{abstract}
This article presents a study that proposes a guide for the design of digital infographics applicable to professional and technological education. From the analysis of 423 infographics, a repertoire of elements related to the language of infographics was systematized. Data stratification led to the identification of the main basic elements of language and of the main elements that characterize the representation of each type of knowledge. The research provides evidence for the analysis of the demands of knowledge representation and for guiding educators and educational material production teams as for the requirements related to the design and/or to the selection of infographics that might contribute to the objectives of the teaching and learning process.
\end{abstract}

Keywords: infographics, design, professional and technological education

\section{Resumen}

Este artículo relata un estudio que propone un referente para design de infografías digitales aplicables en la educación profesional y tecnológica. A partir del análisis de 423 infografías fue sistematizado un repertorio de elementos del lenguaje de computación gráfica. La estratificación de los datos ha llegado a identificar los principales elementos del lenguaje y de los principales elementos que caracterizan la representación de cada tipo de conocimiento. La investigación proporciona elementos para analizar las demandas de representación del conocimiento y orientar los educadores y los equipos de producción de material didáctico, en cuanto a los requisitos para la creación y la selección o de la infografía que contribuyan a los objetivos de enseñanza y aprendizaje.

Palabras clave: infografía, design, educación profesional y tecnológica 


\section{Introdução}

O presente estudo teve sua reflexão no contexto da educação profissional e tecnológica que, normalmente, depara-se com a contingência de mostrar/demonstrar procedimentos, fluxos, detalhes, componentes e processos de difícil visualização. Isso porque, eles podem estar em meio a um conjunto complexo de estruturas e elementos, sendo necessário apresentar enquadramentos específicos, ruídos, conexões e movimentos, partes de um todo.

Para tanto, o planejamento e implementação de estratégias e metodologias que sejam eficientes e eficazes na aprendizagem mediada pelas novas TIC - Tecnologias da Informação e Comunicação é um grande desafio que converge para os processos de aprendizagem centrado no estudante, buscando atender as necessidades individuais através da personalização e interatividade.

O desenho tecnológico e pedagógico das práticas utilizadas para o desenvolvimento de conteúdos curriculares da educação profissional e tecnológica, muitas vezes, necessitam readaptar conteúdos planejados para livros e/ou aulas expositivas, por exemplo, em função de especificidades metodológicas, pedagógicas, técnicas e sociológicas adequadas às situações contextuais de seus cursos.

De acordo com Filatro (2008) o Design Educacional é "o processo (conjunto de atividades) de identificar um problema (necessidade) de aprendizagem e desenhar, implementar e avaliar uma solução para esse problema". A investigação dos princípios de design de infográficos digitais aplicáveis na educação profissional e tecnológica contribui com mais uma possibilidade de solução educacional para as demandas desta área.

Assim, os infográficos digitais apresentam-se como recursos didáticos eficazes para apresentar conteúdos mais complexos e específicos, combinando múltiplos recursos como gráficos, animações, vídeos, áudios, fotomontagens, ilustrações, mapas, entre outros documentos digitalizáveis e multimídia.
Os infográficos podem ser utilizados tanto na educação presencial, na educação a distância (e-learning) como na m-learning (aprendizagem em dispositivos móveis), de fácil integração na maioria dos Ambientes Virtuais de Aprendizagem - AVA, também é muito apropriado para materiais didáticos impressos.

Existem inúmeros infográficos disponibilizados na Web, que podem ser utilizados como fonte de pesquisa e informação, conteúdo complementar e alternativo para aprofundar discussões e atividades didáticas. Além disso, existem softwares gratuitos para a produção de alguns tipos de infográficos que podem veicular conteúdos do programa curricular. Os estudos de Bottentuit Junior nos apontam que:

\begin{abstract}
A utilização de infográficos como um recurso pedagógico alinha-se no atual contexto dos jovens estudantes que complementam sua formação em recursos advindos da Web, tais como vídeos, redes sociais, enciclopédias eletrônicas, imagens, etc. Tais recursos poderão ser visualizados nos infográficos mais modernos, os quais permitem a combinação desses aplicativos com o intuito de favorecer a aprendizagem ou a complementação dos conteúdos ministrados em sala de aula. (BOTTENTUIT JUNIOR et al. 2011)
\end{abstract}

A partir dessas reflexões e da experiência profissional dos pesquisadores foi realizado o referencial para design de infográficos digitais aplicáveis na educação profissional e tecnológica. Por meio deste estudo, espera-se contribuir para o trabalho de planejamento educacional de educadores, designers educacionais e equipes multidisciplinares de produção de material didático, na seleção, demanda e criação de infográficos para aprendizagem.

\section{Infografia}

Os infográficos são formas de representação e visualização de informações e têm sido um recurso muito utilizado pelo jornalismo impresso, porque permite analisar um fato, situação ou notícia de forma detalhada nas suas diversas fases e repercussões. Atualmente, através do webjornalismo, os infográficos evoluíram, 
adotando recursos multimidiáticos sintonizados com a linguagem digital.

Além do contexto jornalístico (impresso ou digital) os infográficos têm sido utilizados em editoriais, informes, manuais de instruções e catálogos empresariais, no design de produtos, na divulgação científica, na tecnologia da informação, por empresas de comunicação e entretenimento, na publicidade, engenharia, saúde, ciência, tecnologia, estatística, política, cultura e variedades, assim como na educação presencial e on-line (Bottentuit Junior et al. 2011), notadamente por sua eficiência no processo comunicacional.

Analisando inúmeros estudos sobre infografia percebe-se que ainda existe a busca por um conceito definitivo que possa superar polêmicas como a levantada por Cairo (2008, p.21), que prefere o termo Visualização de Informação, tendo em vista que o termo infografia deriva do inglês infographics e pode ser confundida com o uso da informática na produção de gráficos. Por outro lado, alguns autores consideram a infografia um gênero jornalístico, enquanto outros a consideram uma técnica, uma linguagem (RIBAS, 2005).

Sinteticamente, podemos dizer que a Infografia (ou infográficos) são representações visuais de informação. A infografia pode transformar uma informação, conteúdo e dados complexos numa apresentação dinâmica e organizada, de tal forma a produzir sentido. As informações jornalísticas, técnicas, educativas ou científicas são exemplos de sua potencial utilização.

Embora o conceito de infografia ainda tenha definições com significações diversas, podemos constatar que existe uma convergência em torno de uma caracterização básica que é a representação de uma informação com apoio de imagens, textos e recursos multimídia e digitais.

Autores como De Pablos (1991), Peltzer (1991) e Valero Sancho (2003) defendem a infografia como publicação independente, considerando-a como "gênero informativo visual", expresso em uma unidade de informação única que carrega variações próprias e responde aos modelos narrativos e descritivos de forma diversa.

\section{Linguagem infográfica}

A linguagem pode se referir tanto à capacidade especificamente humana para aquisição e utilização de sistemas complexos de comunicação, quanto a uma instância específica de um sistema de comunicação complexo (HOUAISS, 1991). Nesse sentido, podemos afirmar que a infografia reúne elementos comunicacionais que fazem parte de múltiplas linguagens e, através de uma articulação intencional, apresenta-se como uma nova possibilidade de leitura e compreensão imediata.

A infografia apresenta-se como uma alternativa capaz de efetivar uma comunicação com diversos públicos, quando usada nos meios de comunicação de massa ou como uma estratégia didática para apoiar a aprendizagem. Assim, deve ser vista através de uma perspectiva da apreensão de uma informação ou de dados mais complexos, em uma sociedade cada vez mais imediatista e, substancialmente familiarizada com a linguagem visual e mensagens objetivas.

No jornalismo, o infográfico é usado para informar um fato para o leitor de determinado segmento social. Quando o infográfico é pensado para a educação, percebe-se o quanto a flexibilidade da linguagem é apropriada para mostrar o funcionamento de um motor, por exemplo, para o estudante de um curso de engenharia mecânica, assim como para um estudante de ensino médio, atendendo a demanda cognitiva e a necessidade da aprendizagem de cada um. A carga conceitual e tecnológica inserida no infográfico pode ser adaptada conforme as características do nível de ensino que o estudante está cursando.

A integração dos elementos da infografia considerando, genericamente, entre um texto e uma imagem ocorre quando ambos são apreendidos como um todo, de tal forma que a sua dissociação comprometerá a compreensão do conteúdo. Santaella e Nöth (2008) apregoam que existem três condições de integração do texto com a imagem: a redundância, a informatividade e a complementaridade.

A redundância acontece quando a imagem apenas ilustra ou repete a informação do texto, sua eliminação 
não muda a compreensão do texto. A informatividade, ao contrário, a imagem é mais informativa que o texto, preponderando-o. E, a complementaridade integra texto e imagem, pois, ambos têm a mesma importância para que a informação possa ser compreendida.

A infografia utiliza, predominantemente, a imagem e o texto de forma amalgamada, sendo imprescindível sua integração e complementaridade. Um texto elaborado para um infográfico terá sentido se estiver associado à imagem que justifica sua existência e, vice-versa. Portanto, o sentido completo da informação a ser transmitida dar-se-á, obrigatoriamente, da apreensão deste conjunto articulado.

A infografia favorece os processos educativos que priorizem cenários e práticas mais próximas do estudante, que já chega às instituições de ensino profissional com um olhar permeado da linguagem infográfica. Esta linguagem está em toda parte e sempre esteve de uma forma ou outra, acompanhando a evolução da humanidade.

\section{Ensino e aprendizagem}

Historicamente, a educação profissional busca implementar novas formas e processos de ensino-aprendizagem que atendam às necessidades da sociedade. A mediação tecnológica advinda da aprendizagem eletrônica (e-learning) é uma realidade na maioria das instituições de educação profissional, em particular, através da modalidade a distância.

A experiência que vem sendo acumulada através da modalidade a distância contribui para adoção de procedimentos e metodologias educacionais desenvolvidas a partir de mídias digitais e que podem ampliar e enriquecer as práticas e processos de aprendizagem.

A busca de equilíbrio deve ser uma constante no processo educacional, em todos os níveis, para enfrentar as demandas da educação, da sociedade e do trabalho. A educação profissional demanda muitos desafios aos educadores no tratamento de assuntos complexos, nos quais processos, fluxos e experimentos não são possíveis de serem explicados apenas com imagens estáticas e exposição oral.
Os educadores e equipes de produção de materiais didáticos necessitam orientações e referenciais que assegurem a aprendizagem significativa, contextualizada e em sintonia com os parâmetros curriculares institucionais, as especificidades de cada área/curso e as exigências da vida contemporânea. Nesse ponto reflete-se: Os estudantes aprendem mais por meio de mensagens multimídia do que somente por mensagens verbais? Em que condições é benéfico juntar imagens às palavras?

Estas, entre outras, questões encontram respostas nos estudos de Mayer (2001) que se fundamentam na hipótese de que as mensagens educacionais multimídia, concebidas ou geradas, baseadas na forma como a mente humana funciona, têm mais probabilidade de levar a uma aprendizagem significativa, conforme afirma:

\begin{abstract}
Aprendizagem Multimídia ocorre quando os estudantes constroem representações mentais de palavras e imagens que são apresentadas a eles (exemplo: textos impressos e ilustrações ou narração e animação). A promessa de aprendizagem multimídia é que os estudantes podem aprender mais profundamente de multimensagens de mídia bem concebidas consistindo em palavras e imagens do que de modos mais tradicionais de comunicação envolvendo apenas palavras. (MAYER, 2001)
\end{abstract}

Metodologicamente, Mayer propõe sete princípios que devem estar subjacentes à concepção de um documento multimídia, são eles: Princípio Multimídia, Princípio de Proximidade Espacial, Princípio de proximidade temporal, Princípio da coerência, Princípio de modalidade, Princípio de redundância e o Princípio das diferenças individuais.

O Princípio Multimídia, no qual os estudantes aprendem melhor quando se combinam palavras e imagens do que só palavras. A apresentação de texto e imagem permite o estabelecimento de relações entre ambas. Os estudantes aprendem melhor quando à animação se junta à narração.

O Princípio de proximidade espacial (ou contiguidade): nele, palavras e imagens correspondentes estão próximas em vez de afastadas (numa página ou tela). As imagens e textos devem ser apresentados em simultâneo, não em sequência. 
O Princípio de proximidade temporal é quando palavras e imagens são apresentadas, simultaneamente, em vez de sucessivamente.

O Princípio da coerência: Quando palavras, imagens ou sons não relevantes para o assunto são excluídos, como por exemplo: música de fundo.

O Princípio de modalidade: Quando se utiliza animação e narração em vez de animação e texto escrito; numa apresentação multimídia é melhor apresentar as palavras sob a forma de narração auditiva em vez de texto na tela. $\mathrm{O}$ texto na tela é uma representação visual e sobrecarrega o canal viso-espacial (efeito da atenção dividida).

Já, o Princípio de redundância, que é quando se utiliza animação e narração em vez de animação, narração e texto. $\mathrm{A}$ adição de texto numa animação narrada não promove a compreensão e pode diminuí-la. O texto escrito juntamente com o mesmo texto narrado divide a atenção.

Por fim, o Princípio das diferenças individuais (ou personalização) é aquele em que os estudantes aprendem mais profundamente a partir de uma explicação multimídia quando as palavras são apresentadas num estilo coloquial do que num estilo formal.

Os sistemas simbólicos das mídias influenciam a aquisição do conhecimento de diferentes modos, não apenas quando representam o conhecimento, mas também pelo papel diferenciado que desempenham nas atividades mentais que desencadeiam e, consequentemente, na aprendizagem. Pereira reflete sobre isso:

O que a investigação de Mayer permite concluir é que os estudantes aprendem menos quando o único meio / mídia disponível para a aprendizagem é o verbal e que se a mesma informação for apoiada noutros meios /mídias a aprendizagem se torna mais proveitosa. Por exemplo, palavras (texto impresso ou discurso oral) apoiadas por imagens (estáticas ou animadas) ou quaisquer outros suportes / meios / mídias permitem um acréscimo significativo, mensurável, das apren- dizagens. Note-se que não se trata necessariamente do recurso a novas tecnologias para melhorar as aprendizagens: mesmo um livro com texto e imagem permite acréscimos significativos em comparação com um livro baseado apenas em texto escrito. (PEREIRA et al., 2011)

Cabe destacar que cada etapa da aprendizagem requer um tratamento particularizado. Um recurso digital pode ser usado para demonstrar um processo ou conceito em determinado momento, mas pode não ser uma boa escoIha para uma introdução ou aprofundamento de um assunto, por exemplo. $O$ educador deve avaliar em quais situações e decidir o que é mais conveniente para o planejamento educacional e as melhores condições de aplicação.

Destaca-se a afinidade da linguagem infográfica com os princípios elencados por Mayer (2001), em especial, quando preconiza que o uso de imagens e textos deve ser apresentado em simultâneo, não em sequência (princípio de proximidade espacial ou contiguidade) e que palavras e imagens devem ser apresentadas, simultaneamente, em vez de sucessivamente (princípio de proximidade temporal).

\section{O caminho da pesquisa}

Os infográficos publicados nos e-books da INFOLIDE Mostra Nacional de Infográficos foram o lócus da investigação. A Mostra foi criada em 2007, por Mário Kanno, professor e editor de arte do jornal Folha de São Paulo. A ideia da mostra, segundo Kanno, surgiu para fazer jus a qualidade gráfica e informativa dos trabalhos produzidos no país e que são amplamente premiados em eventos como Society for News Design-SND (EUA) e Malofiej (Espanha) que premiam os melhores da infografia mundial.

Para a análise foram selecionados os infográficos que figuraram nas mostras da INFOLIDE, biênio 2012-2013, num total de quatrocentos e vinte e três (423) infográficos de autores brasileiros. Na tabela 1 é apresentada a síntese dos dados compilados reunindo o número de infográficos em cada ano e nas respectivas categorias da Mostra. 
Tabela 1: Número de Infográficos Analisados

\begin{tabular}{|l|c|c|c|}
\hline \multicolumn{1}{|c|}{ INFOGRÁFICOS } & 2012 & 2013 & TOTAIS \\
\hline Agências & 02 & 24 & 26 \\
Editoras & 13 & 06 & 19 \\
Jornais & 98 & 67 & 165 \\
Revistas & 67 & 47 & 114 \\
Sites & 60 & 39 & 99 \\
TOTAIS & 240 & 183 & 423 \\
\hline
\end{tabular}

Fonte: Dados da Mostra INFOLIDE 2012-2013 compilados pela autora

O procedimento padrão para analise foi organizado em sete (7) etapas, sintetizadas no fluxograma (figura 1).

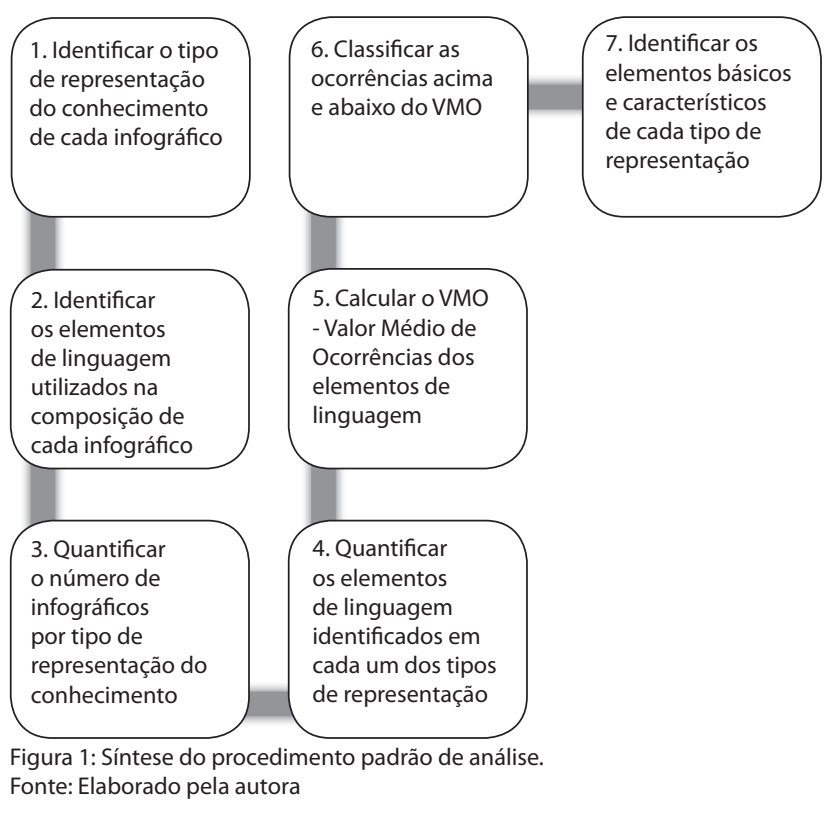

A tipificação das demandas de representação do conhecimento (1) e o repertório de elementos de linguagem dos infográficos (2) formaram a estrutura de encaminhamento do movimento da pesquisa. Foi um procedimento construído a partir da experiência educacional dos pesquisadores, da observação de inúmeros infográficos e da revisão do estado da arte de estudos sobre infográficos na educação. A seguir aprofundamos estes tópicos.

\section{Tipos de Demanda de Representação do Conhecimento}

A tipificação das demandas do conhecimento apresenta-se como uma ferramenta para o educador ou designer educacional de uma equipe de produção de materiais didáticos, enquanto etapa de planejamento.
Ao compreender-se o tipo de necessidade (demanda) que o conteúdo curricular (conhecimento) requer para determinado objetivo de aprendizagem pode-se, de forma mais eficiente, determinar ou selecionar uma representação.

Salienta-se que essa ferramenta pode ser utilizada para tomada de decisão em qualquer forma de representação do conhecimento, por exemplo, texto; vídeo; exposição oral; entre outras. Neste estudo, os infográficos são a forma de representação que foi avaliada. De qualquer forma vale lembrar o que diz Kanno:

O infográfico não tem o poder milagroso de 'fazer coisas complexas ficarem simples', ele é apenas a melhor maneira de representar certo tipo de informação. Da mesma forma que o texto é o meio mais eficaz de descrever outros tipos de informação e a foto é mais eficiente em outros casos. (KANNO, 2013 p. 11)

Que tipos de conhecimento estão representados neste infográfico? Esta pergunta deu inicio a investigação e daí foi construída uma visão sobre os tipos de conhecimento que frequentemente dão origem aos infográficos como estratégia de representação. A representação do conhecimento normalmente é apresentada por textos. $\mathrm{Na}$ infografia, além do texto, é utilizado um conjunto de representações visuais para transmitir a informação.

O educador em seus programas curriculares muitas vezes depara-se com demandas do conhecimento que necessitam uma representação para além do texto como forma de apoio na implementação de um processo específico de aprendizagem.

Na revisão de literatura não foi encontrada uma fonte única e convergente que reunisse critérios de classificação sobre as demandas de representação do conhecimento. Esse fato impulsionou um movimento da pesquisa no sentido de criar critérios próprios de classificação que atendessem a demanda de design educacional.

Da mesma forma, na busca de referência sobre os elementos de linguagem, foram encontrados poucos e dispersos elementos de classificação, novamente foi impulsionada a construção de um olhar crítico e de classificação que permitisse dar conta desta necessidade. 
Para estabelecer uma estratégia de reflexão partiu-se da experiência dos pesquisadores, especificamente na perspectiva do design educacional para o tratamento de demandas de diversos tipos de conhecimento e da observação dos infográficos. Dessa forma, chegou-se em seis (6) grandes tipos: Temporal; Lógico; Funcional; Científico; Natural; e Sociocultural.

$\mathrm{Na}$ classificação das demandas de representação do conhecimento (tabela 2), são apresentados os conceitos que desenvolvidos para identificar os seis tipos de demandas e possíveis enfoques delimitadores.

Tabela 2: Classificação das Demandas de Representação do Conhecimento

\begin{tabular}{|c|c|}
\hline \multicolumn{2}{|c|}{ DEMANDAS DE REPRESENTAÇÃO DO CONHECIMENTO } \\
\hline TIPOS & ENFOQUES \\
\hline $\begin{array}{l}\text { TEMPORAL: Explicar } \\
\text { posições sequenciais ou } \\
\text { relações causais no tempo. }\end{array}$ & $\begin{array}{l}\text { - Mostrar progressão cronológica ou histórica; } \\
\text { - Mostrar mudanças de relações, ações, } \\
\text { movimentos, fluxos através do tempo; } \\
\text { - Mostrar sucessão de eventos, ações e relações } \\
\text { de causa. }\end{array}$ \\
\hline $\begin{array}{l}\text { LÓGICO: Explicar escalas, } \\
\text { proporções, mudanças e a } \\
\text { organização de dados no } \\
\text { espaço, tempo ou ambos. }\end{array}$ & $\begin{array}{l}\text { - Organizar fatos e números coletados, } \\
\text { analisados e sintetizados para apresentação e } \\
\text { interpretação; } \\
\text { - Demonstrar combinação de partes que, } \\
\text { coordenadas, concorrem para um fim; } \\
\text { - Mostrar sucessão de eventos, ações e relações } \\
\text { de causa. }\end{array}$ \\
\hline $\begin{array}{l}\text { FUNCIONAL: Explicar } \\
\text { posições e relações } \\
\text { espaciais em uma locação } \\
\text { física ou conceitual. }\end{array}$ & $\begin{array}{l}\text { - Mostrar conjunto sequencial de ações/ } \\
\text { procedimentos que permitem realizar um } \\
\text { trabalho de forma correta e atingir uma meta; } \\
\text { - Mostrar interações passo-a-passo através do } \\
\text { espaço e tempo; } \\
\text { - Mostrar sucessão de eventos, ações e relações } \\
\text { de causa. }\end{array}$ \\
\hline $\begin{array}{l}\text { CIENTÍFICO: Explicar } \\
\text { eventos, sistemas, } \\
\text { processos meteorológicos, } \\
\text { elétricos, físicos, } \\
\text { geológicos, hidrológicos, } \\
\text { óticos, químicos, térmicos, } \\
\text { eletrônicos, informático- } \\
\text { digitais, mecânicos, } \\
\text { construtivos (engenharia/ } \\
\text { arquitetura), astronômicos. }\end{array}$ & $\begin{array}{l}\text { - Mostrar detalhes observáveis, interna e } \\
\text { externamente; } \\
\text { - Mostrar detalhes de um ponto de vista } \\
\text { normalmente não possível para o olho } \\
\text { humano; } \\
\text { - Mostrar sucessão de eventos, ações e relações } \\
\text { de causa. }\end{array}$ \\
\hline $\begin{array}{l}\text { NATURAL: Explicar } \\
\text { organismos, sistemas } \\
\text { vivos, fenômenos } \\
\text { biológicos, ambientais, } \\
\text { ecológicos. }\end{array}$ & $\begin{array}{l}\text { - Mostrar detalhes observáveis, interna e } \\
\text { externamente; } \\
\text { - Mostrar detalhes de um ponto de vista } \\
\text { normalmente não possível para o olho } \\
\text { humano; } \\
\text { - Mostrar sucessão de eventos, ações e relações } \\
\text { de causa. }\end{array}$ \\
\hline $\begin{array}{l}\text { SOCIOCULTURAL: Explicar } \\
\text { eventos, fatos, processos, } \\
\text { sistemas social, político, } \\
\text { econômico, cultural. }\end{array}$ & $\begin{array}{l}\text { - Mostrar detalhes da interação de seres } \\
\text { humanos na sociedade; } \\
\text { - Mostrar sucessão de eventos, ações e relações } \\
\text { de causa. }\end{array}$ \\
\hline
\end{tabular}

Fonte: Elaborada pela autora.

Os conceitos desenvolvidos não são exclusivos, nem contemplam a infindável gama de demandas que podem suscitar das diversas áreas do conhecimento. Notadamente, essa conceituação foi baseada no olhar que construído sobre infográficos e a expectativa de atender necessidades de representação do conhecimento em programas curriculares da educação profissional e tecnológica.

\section{Repertório de Elementos de Linguagem}

Para o desenvolvimento da pesquisa sentiu-se a necessidade de categorizar o repertório de elementos de linguagem. Assim, foram criadas dez (10) grandes categorias, que emergiram dos dados dos infográficos analisados. Um parâmetro de análise muito útil, que permitiu ver a recorrência dos elementos, por tipo de necessidade de representação do conhecimento.

Estas dez categorias reúnem os seguintes elementos de linguagem dos infográficos, a saber: mapas, tipografia, gráficos, fotografia, diagramas, texto, elementos básicos da linguagem visual, ilustrações, efeitos e elementos básicos da linguagem digital.

Os elementos de linguagem são combinados entre si para constituírem soluções visuais que garantam a comunicação. As soluções surgem a partir de sobreposições, alinhamentos, repetições, justaposições, contrastes e imbricamentos dos elementos de linguagem para estabelecer relações, ações, sucessões, interações, movimentos, fluxos, processos, progressões, hierarquias, procedimentos e qualquer outra necessidade de representação.

O repertório dos elementos de linguagem reunido neste tópico é resultante da observação de inúmeros infográficos disponíveis em publicações da web. Este processo foi a etapa inicial deste estudo. Possivelmente muitos elementos de linguagem não foram considerados, tão pouco as descrições de cada elemento aqui apresentadas são definitivas, ao contrário, são passíveis de reavaliações e ressignificações.

Os elementos de linguagem estão reunidos sinteticamente na tabela 3 apresentando as 10 (dez) categorias e suas respectivas 73 (setenta e três) subcategorias para uma visualização mais simples e consulta rápida. 
Tabela 3: Síntese do Repertório dos Elementos de Linguagem

\begin{tabular}{|c|c|}
\hline CATEGORIAS & SUBCATEGORIAS \\
\hline MAPAS & $\begin{array}{l}\text { Mapa Geográfico } \\
\text { Mapa de Localização }\end{array}$ \\
\hline TIPOGRAFIA & $\begin{array}{l}\text { Marcadores } \\
\text { Variação de Fontes } \\
\text { Variação do Tamanho de Fontes } \\
\text { Uso de Bold } \\
\text { Uso de Itálico }\end{array}$ \\
\hline GRÁFICOS & $\begin{array}{l}\text { Linha } \\
\text { Barra/Coluna } \\
\text { Dispersão } \\
\text { Pizza } \\
\text { Área } \\
\text { Múltiplos } \\
\text { Radar }\end{array}$ \\
\hline FOTOGRAFIA & $\begin{array}{l}\text { Fotografia Padrão } \\
\text { Fotomontagem }\end{array}$ \\
\hline DIAGRAMAS & $\begin{array}{l}\text { Fluxograma } \\
\text { Organograma } \\
\text { Estereograma } \\
\text { Cartograma } \\
\text { Radial } \\
\text { Timeline } \\
\end{array}$ \\
\hline TEXTOS & $\begin{array}{l}\text { Bullets } \\
\text { Lista } \\
\text { Tabela } \\
\text { Numeração } \\
\text { Resumo } \\
\text { Legenda } \\
\text { Cronologia } \\
\text { Título } \\
\text { Descrição } \\
\end{array}$ \\
\hline $\begin{array}{l}\text { ELEMENTOS } \\
\text { BÁSICOS DA } \\
\text { LINGUAGEM } \\
\text { VISUAL (EBLV) }\end{array}$ & $\begin{array}{l}\text { Ponto } \\
\text { Linha } \\
\text { Formas Geométricas Básicas } \\
\text { Direção } \\
\text { Dimensão } \\
\text { Movimento } \\
\text { Escala } \\
\text { Textura } \\
\text { Cor } \\
\text { Tom } \\
\text { Grid Visível }\end{array}$ \\
\hline ILUSTRAÇÕES & $\begin{array}{l}\text { Ícone/Símbolo } \\
\text { Pictograma } \\
\text { Realista } \\
\text { Metáfora } \\
\text { Simplificada } \\
\text { Storyboard/História em Quadrinhos }\end{array}$ \\
\hline EFEITOS & $\begin{array}{l}\text { Raio - X } \\
\text { Corte } \\
\text { Zoom/lupa } \\
\text { Perspectiva Impossível } \\
\text { Simultaneidade } \\
\text { Transparência } \\
\text { Deformação } \\
\end{array}$ \\
\hline $\begin{array}{l}\text { ELEMENTOS } \\
\text { BÁSICOS DA } \\
\text { LINGUAGEM } \\
\text { DIGITAL (EBLD) }\end{array}$ & $\begin{array}{l}\text { Link Contextual } \\
\text { Link Externo } \\
\text { Menus } \\
\text { Games/Quizzes } \\
\text { Zoom Dinâmico } \\
\text { Animação } \\
\text { Simulação } \\
\text { Download/Embed } \\
\text { Instrução de Uso } \\
\text { Storytelling } \\
\text { Áudio } \\
\text { Barra de Rolagem } \\
\text { Barra de Progresso } \\
\text { Vídeo } \\
\text { Arrastar e Soltar } \\
\text { Videográfico (on demand) } \\
\text { Mouseover } \\
\text { Timeline Dinâmica } \\
\end{array}$ \\
\hline
\end{tabular}

A necessidade de criar o repertório de elementos fundamentou-se na intenção de conhecer mais profundamente a linguagem infográfica e com isso ampliar a compreensão sobre suas possibilidades na representação do conhecimento no meio educacional. No próximo tópico constam imagens de infográficos para exemplificar os elementos de linguagem.

\section{Análise dos Infográficos}

Os elementos de linguagem classificados na etapa anterior da pesquisa formaram o repertório utilizado para a análise dos infográficos da Mostra INFOLIDE. Esse movimento de pesquisa foi indispensável para validar a utilidade e viabilidade dos critérios de classificação construído pelos pesquisadores. Observa-se que os infográficos podem conter demandas de representação múltiplas, tanto no que diz respeito aos diversos enfoques que o assunto pode ter, bem como os inúmeros elementos de linguagem que entram na criação da composição infográfica.

Para exemplificar os elementos mapeados nos 423 infográficos foram selecionadas três imagens a seguir:

\section{a) Infográfico “A casa de US\$ 6 mil”}

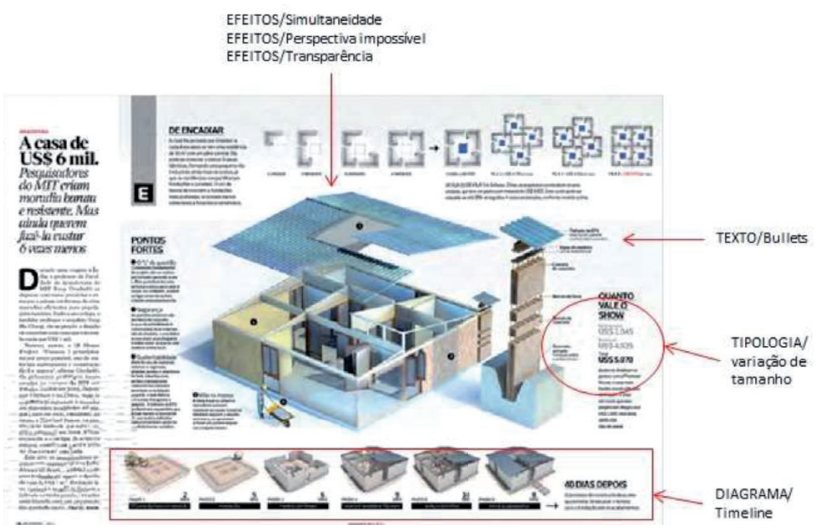

Figura 2: Infográfico [303] "A casa de US\$ 6 mil".

Fonte: 6a INFOLIDE 2012. Revista Galileu. Publicação: fev/2012.

Autores: Ricardo Martins, Anna Luiza Aragão, Gerson Mora e Rafael Tonon.

Intervenção da autora: Destaques em linhas vermelhas para assinalar elementos de linguagem

Este infográfico (figura 2) utiliza efeitos como simultaneidade, perspectiva impossível e transparência que são estratégias visuais para mostrar ângulos impossíveis. No texto apa- 
recem bullets, pequenos textos informativos que destacam de forma muito sucinta algum aspecto da figura. A variação de tamanho de fonte no texto é uma estratégia para chamar a atenção de dados específicos. Na parte inferior do infográfico podemos observar uma linha do tempo (timeline) formada pelas diferentes fases de construção da casa.

\section{b) Infográfico “O fim das lembranças”}

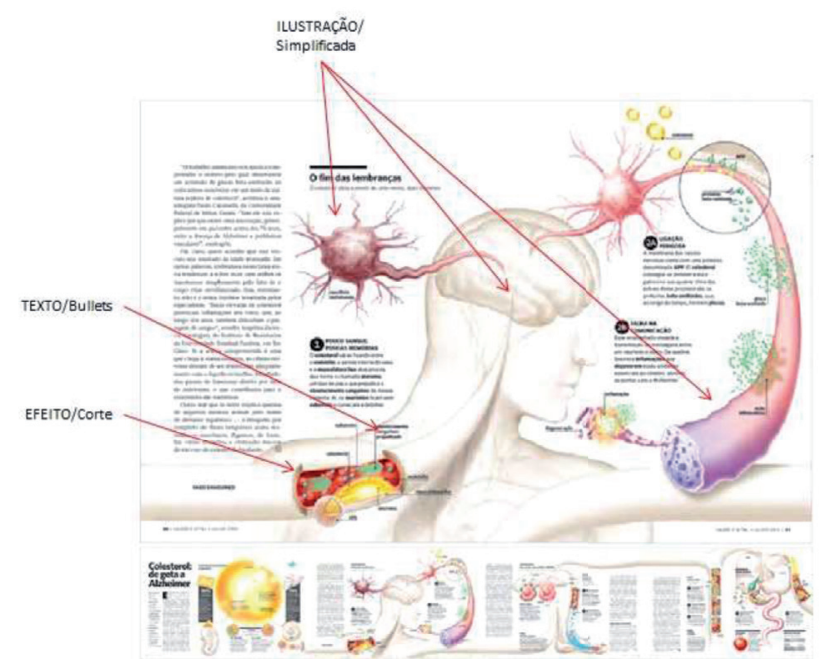

Figura 3: Infográfico [325] "O fim das lembranças".

Fonte: 6a INFOLIDE 2012. Revista Saúde. Publicação: jul/2012.

Autores: Pilker, Erika Onodera e Theo Ruprecht. Intervenção da autora: Desta-

ques em linhas vermelhas para assinalar elementos de linguagem

Neste infográfico (figura 3) são tratados alguns estados de funcionamento de partes do cérebro humano. A ilustração simplificada preocupa-se em esquematizar a forma para que a interpretação seja direta. O efeito de corte é usado a fim de dar destaque para estruturas não visíveis ao olho humano. Mais uma vez podemos observar a estratégia do uso de bullets para destacar informações curtas próximas à ilustração. c) Infográfico "A água que você usa por dia: 7887 litros"

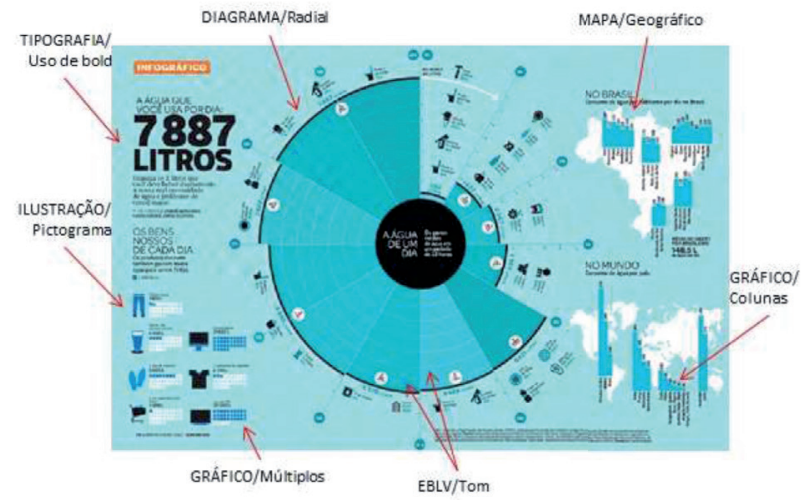

Figura 4: Infográfico [329] "A água que você usa por dia: 7887 litros". Fonte: 6a INFOLIDE 2012. Revista Superinteressante. Publicação: fev/2012. Autores: André Bernardo, Karin Hueck e Jorge Oliveira. Intervenção da autora: Destaques em linhas vermelhas para assinalar elementos de linguagem

Neste infográfico (figura 4) observamos um diagrama radial, cada radiano vai pontuando os diferentes usos e quantidades de água utilizadas durante um dia. Além dos dados contidos os períodos de tempo são enfatizados por diferentes tons da cor azul. As ilustrações aparecem como pictogramas (esquematizadas) acompanhando o estilo abstrato do infográfico. Também os mapas geográficos e os gráficos de coluna são representados de forma bem simplificada e informam os dados de consumo diário nas regiões do Brasil e continentes.

$\mathrm{Na}$ análise dos infográficos foram identificados cada um dos elementos de linguagem compilados no repertório apresentado na tabela 3. Cada um dos 423 infográficos teve a identificação de todos os elementos de linguagem como processo da investigação que construiu um olhar crítico sobre a linguagem infográfica. 


\section{Considerações finais}

O presente estudo fornece elementos para analisar as demandas de representação do conhecimento e orientar educadores e equipes de produção de material didático quanto aos requisitos para criação e ou seleção de infográficos que venham contribuir com os seus objetivos de ensino-aprendizagem.

Os movimentos de análise sobre a coletânea de infográficos permitiu validar os critérios de classificação dos tipos de representação do conhecimento e dos elementos de linguagem através de um olhar crítico sobre a linguagem infográfica.

- Contribuições

- Repertório de tipos de demandas de representação do conhecimento: Temporal, Lógico, Funcional, Científico, Natural e Sociocultural;

- Repertório de elementos de linguagem da infografia: Elementos Básicos e Elementos Característicos dos Tipos de Representação do Conhecimento.
A sistematização da investigação criou um referencial para design de infográficos digitais estratificando dados para a identificação dos principais elementos básicos de linguagem e dos principais elementos característicos da representação de cada tipo de conhecimento, conforme apresentado na síntese a seguir.

A necessidade de criar um repertório de elementos de linguagem e de tipos de representação do conhecimento foi fundamentada na intenção de conhecer mais profundamente a linguagem infográfica e com isso ampliar a compreensão sobre suas possibilidades de aplicação no meio educacional.

A partir do estudo realizado obteve-se um referencial para o planejamento educacional, na criação e ou seleção de um infográfico já existente. Os educadores ou designers de equipes de produção de material didático poderão identificar os elementos de linguagem e as formas compositivas que são utilizadas para a representação da informação.

Tabela 4: Síntese dos Elementos de Linguagem Básicos e Elementos Característicos dos seis (6) tipos de Representação do Conhecimento

\begin{tabular}{|c|c|c|c|c|c|c|}
\hline \multirow{2}{*}{$\begin{array}{l}\text { ELEMENTOS BÁSICOS DE } \\
\text { LINGUAGEM (existentes em } \\
\text { todas as representações) }\end{array}$} & \multicolumn{6}{|c|}{ ELEMENTOS DE LINGUAGEM CARACTERÍSTICOS DE CADA TIPO DE REPRESENTAÇÃO DO CONHECIMENTO } \\
\hline & TEMPORAL & LÓGICO & FUNCIONAL & CIENTÍ́FICO & NATURAL & SOCIOCULTURAL \\
\hline MAPA [Geográfico] & DIAGRAMA [Timeline] & $\begin{array}{l}\text { GRÁFICO [Linha/ } \\
\text { Barra/coluna/Pizza] }\end{array}$ & MAPA [Localização] & MAPA [Localização] & $\begin{array}{l}\text { TEXTO [Tabela/ } \\
\text { Numeração] }\end{array}$ & $\begin{array}{l}\text { MAPA } \\
\text { [Localização] }\end{array}$ \\
\hline FOTOGRAFIA [Formato Patrão] & $\begin{array}{l}\text { TEXTO [Lista/Legenda/ } \\
\text { Cronologia] }\end{array}$ & $\begin{array}{l}\text { FOTOGRAFIA } \\
\text { [Fotomontagem] }\end{array}$ & $\begin{array}{l}\text { FOTOGRAFIA } \\
\text { [Fotomontagem] }\end{array}$ & $\begin{array}{l}\text { FOTOGRAFIA } \\
\text { [Fotomontagem] }\end{array}$ & $\begin{array}{l}\text { EBLV [Ponto/Direção/ } \\
\text { Movimento/Textura] }\end{array}$ & $\begin{array}{l}\text { TEXTO } \\
\text { [Numeração/ } \\
\text { Legenda] }\end{array}$ \\
\hline $\begin{array}{l}\text { TIPOGRAFIA [Variação do tipo } \\
\text { de fonte/Variação do tamanho } \\
\text { da fonte/Uso de bold] }\end{array}$ & EBLV [Ponto/Textura] & $\begin{array}{l}\text { TEXTO [Tabela/ } \\
\text { Numeração/ } \\
\text { Legenda] }\end{array}$ & $\begin{array}{l}\text { TEXTO } \\
\text { [Numeração/ } \\
\text { Cronologia] }\end{array}$ & TEXTO [Numeração] & $\begin{array}{l}\text { ILUSTRAÇÃO } \\
\text { [Pictograma/Realista/ } \\
\text { Simplificada] }\end{array}$ & $\begin{array}{l}\text { EBLV [Ponto/ } \\
\text { Direção/Textura] }\end{array}$ \\
\hline $\begin{array}{l}\text { TEXTO [Bullets/Resumo/ } \\
\text { Introdução/Título/subtítulo/ } \\
\text { Descrição }\end{array}$ & $\begin{array}{l}\text { ILUSTRAÇÃO [Ícone/ } \\
\text { símbolo/Pictograma/ } \\
\text { Realista] }\end{array}$ & EBLV [Ponto] & $\begin{array}{l}\text { EBLV [Direção/ } \\
\text { Dimensão/Textura] }\end{array}$ & $\begin{array}{l}\text { EBLV [Ponto/Direção/ } \\
\text { Dimensão/Escala/ } \\
\text { proporção/Textura] }\end{array}$ & $\begin{array}{l}\text { EFEITO [Raio-X/Corte/ } \\
\text { Zoom/lupa] }\end{array}$ & $\begin{array}{l}\text { ILUSTRAÇÃO } \\
\text { [Pictograma/ } \\
\text { Realista/ } \\
\text { Simplificada] }\end{array}$ \\
\hline $\begin{array}{l}\text { EBLV [Linha/Formas } \\
\text { geométricas/Cor/Tom] }\end{array}$ & $\begin{array}{l}\text { EBLD [Animação/ } \\
\text { Instrução de Uso/ } \\
\text { Vídeo/Timeline } \\
\text { dinâmica] } \\
\end{array}$ & $\begin{array}{l}\text { ILUSTRAÇÃO } \\
\text { [Ícone/símbolo/ } \\
\text { Pictograma/ } \\
\text { Simplificada] }\end{array}$ & $\begin{array}{l}\text { ILUSTRAÇÃO } \\
\text { [Ícone/símbolo/ } \\
\text { Pictograma/ } \\
\text { Simplificada] }\end{array}$ & $\begin{array}{l}\text { ILUSTRAÇÃO [Ícone/ } \\
\text { símbolo/Pictograma/ } \\
\text { Simplificada] }\end{array}$ & $\begin{array}{l}\text { EBLD [Instrução de } \\
\text { Uso/Vídeo/Arrastar } \\
\text { e soltar/Mouseover/ } \\
\text { Timeline dinâmica] }\end{array}$ & $\begin{array}{l}\text { EBLD [Animação/ } \\
\text { Barra de rolagem/ } \\
\text { Videográfico (on } \\
\text { demand)] }\end{array}$ \\
\hline $\begin{array}{l}\text { EBLD [Link Contextual/Link } \\
\text { Externo/Menus] }\end{array}$ & & $\begin{array}{l}\text { EFEITO } \\
\text { [Simultaneidade] }\end{array}$ & $\begin{array}{l}\text { EFEITO [Corte/ } \\
\text { Zoom/lupa/ } \\
\text { Perspectiva } \\
\text { impossível/ } \\
\text { Simultaneidade] }\end{array}$ & $\begin{array}{l}\text { EFEITO [Corte/Zoom/ } \\
\text { lupa/Perspectiva } \\
\text { impossível/ } \\
\text { Simultaneidade/ } \\
\text { Transparência] }\end{array}$ & & \\
\hline & & $\begin{array}{l}\text { EBLD [Animação/ } \\
\text { Instrução de Uso/ } \\
\text { Mouseover] }\end{array}$ & $\begin{array}{l}\text { EBLD [Animação/ } \\
\text { Download/embed/ } \\
\text { Instrução de Uso/ } \\
\text { Áudio/Vídeo/ } \\
\text { Mouseover] }\end{array}$ & $\begin{array}{l}\text { EBLD [Animação/ } \\
\text { Instrução de Uso/ } \\
\text { Vídeo/ } \\
\text { Mouseover/Timeline } \\
\text { dinâmica] }\end{array}$ & & \\
\hline
\end{tabular}


O referencial de design de infográficos digitais qualifica a percepção para a seleção de infográficos mais efetivos para os objetivos propostos, assim como para aqueles que investirem na criação de um infográfico possam assegurar uma eficiência no processo comunicacional do mesmo.

\section{c) Página web}

A página web "infografar" é uma produção gerada pela investigação e disponível em < http://infografar.blogspot.com.br $>$. Lá se encontram informações sobre a pesquisa e as postagens dos 423 infográficos analisados. $\mathrm{O}$ repositório de infográficos classificados por tipo de representação do conhecimento é fonte de pesquisa para estudantes, educadores, designers educacionais e equipes de produção de material didático.

A publicação da página também pode auxiliar educadores e estudantes de disciplinas e cursos da área de design, comunicação e afins. Nesse ponto vale lembrar as palavras de Moraes, professor e especialista em infografia:

A procura por cursos de Design aumentou e boa parte dos jovens que chegam nessas escolas já tem os infográficos como parte de seu repertório. São pessoas que se movem com desenvoltura entre páginas impressas, smartphones, tablets, laptops ou TVs de alta definição e já não lembram do mundo sem esses aparatos, tampouco de jornais sem infográficos. (MORAES, 2013)

A infografia é uma linguagem que cada vez mais ganha espaço nas diversas mídias de comunicação de massa, na educação, na ciência, no setor corporativo, entre muitas outras áreas.

Para além deste estudo, outros pesquisadores poderão adaptar e usar os tipos de representação do conhecimento em outros meios de comunicação aplicáveis na educação. Avaliarem outras coletâneas de infográficos premiados em diferentes países, identificando se a diversidade geográfica e cultural interfere nas representações. O referencial para design de infográficos da presente análise também poderá ser ampliado por outros pesquisadores bem como auxiliar as tomadas de decisão de educadores, designers educacionais e equipes de produção de material didático, no planejamento educacional.

\section{Referências}

BOTTENTUIT JUNIOR, João Batista; LISBOA, Eliana Santana; COUTINHO, Clara Pereira. O Infográfico e as suas Potencialidades Educacionais. IV Encontro Nacional de Hipertexto e Tecnologias Educacionais. Sorocaba, 2011. Disponível em: $<$ http HYPERLINK "http://repositorium.sdum.uminho.pt/bitstream/1822/14858/1/48_JoaoBatista2.pdf":// HYPERLINK "http:// repositorium.sdum.uminho.pt/bitstream/1822/14858/1/48_ JoaoBatista2.pdf"repositorium HYPERLINK "http://repositorium.sdum.uminho.pt/bitstream/1822/14858/1/48_JoaoBatista2.pdf". HYPERLINK "http://repositorium.sdum.uminho. pt/bitstream/1822/14858/1/48_JoaoBatista2.pdf"sdum HYPERLINK "http://repositorium.sdum.uminho.pt/bitstream/1822/14858/1/48_JoaoBatista2.pdf".

uminho HYPERLINK "http://repositorium.sdum.uminho.pt/bitstream/1822/14858/1/48_JoaoBatista2.pdf". HYPERLINK "http:// repositorium.sdum.uminho.pt/bitstream/1822/14858/1/48_ JoaoBatista2.pdf"pt HYPERLINK "http://repositorium.sdum. uminho.pt/bitstream/1822/14858/1/48_JoaoBatista2. pdf"/ HYPERLINK "http://repositorium.sdum.uminho.pt/ bitstream/1822/14858/1/48_JoaoBatista2.pdf"bitstream HYPERLINK "http://repositorium.sdum.uminho.pt/bitstream/1822/14858/1/48_JoaoBatista2.pdf"/1822/14858/1/48_ HYPERLINK "http://repositorium.sdum.uminho.pt/bitstream/1822/14858/1/48_JoaoBatista2.pdf"JoaoBatista HYPERLINK "http://repositorium.sdum.uminho.pt/bitstream/1822/14858/1/48_JoaoBatista2.pdf"2. HYPERLINK "http:// repositorium.sdum.uminho.pt/bitstream/1822/14858/1/48_ JoaoBatista2.pdf"pdf > Acesso: abr2012

CAIRO, Alberto. Infografía 2.0. Editora Alamut. Madrid, 2008.

DE PABLOS, José Manuel. Infoperiodismo: El periodista como creador de infografia. Madri: Editorial Sintesis, 1999.

FILATRO, Andrea. Design Instrucional na Prática. São Paulo: Pearson Education do Brasil, 2008.

HOUAISS, Antônio. O que é Língua. Brasiliense: São Paulo, 1991

MAYER, Richard. Multimedia Learning, Cambridge: Cambridge University Press, 2001.

MORAES, Ary. Infografia: História e Projeto. São Paulo: Blucher, 2013.

PELTZER, Gonzalo. Periodismo Iconográfico. Madrid: Ediciones Rialp, 1991. 
PEREIRA, Francisco; PASCOA, Rui; LAGOA, Sergio; PATROCINIO, Zelia. A promessa de aprendizagem multimédia: usando os mesmos métodos de design instrucional em diferentes meios de comunicação (tradução de: The promise of multimedia learning: using the same instructional design methods across different media by Richard Mayer, 2003). Unidade Curricular de Comunicação Educacional da $5^{\text {a }}$ edição do Mestrado em Pedagogia do HYPERLINK "http://www.univ-ab.pt/guiainformativo/detailcursos.php?curso=39"eLearning HYPERLINK "http://www.univ-ab.pt/guiainformativo/detailcursos. php?curso=39" da Universidade Aberta. Lisboa, 2011. Disponível em: <http://mpel5cegb.

wikispaces.com/3.+Richard+Mayer> Acesso: fev2013

KANNO, Mário. Infografe. Ed. Eletrônica. São Paulo: infolide. com, 2013.

RIBAS, Beatriz. Ser Infográfico: apropriações e limites do conceito de infografia no campo de jornalismo. III Encontro Nacional de Pesquisadores em Jornalismo - SBJor, 2005. Disponível em: http://www.facom.ufba.br/jol/pdf/2005_ribas_sbpjor_florianopolis_serinfografico.pdf. Acesso em: nov2012.

SANTAELLA, Lucia e NÖTH, Winfried. Imagem, Cognição, Semiótica, Mídia. São Paulo: Iluminuras, 1998.

VALERO SANCHO, José Luis. La infografia digital en el comienzo de uma nueva manera de informar. I Congresso de Periodismo Digital Macacay, 2004. Disponível em: http://www.analitica. com/midia/9399701.pdf. Acesso em: dez2012.

Sites:

www.infolide.com

http://infografar.blogspot.com.br

Data de Recebimento: 05 de setembro de 2014

Data de Aprovação: 18 de outubro de 2014

Data de Publicação: 30 de dezembro de 2014 
